\title{
STRATEGY FOR INTERIM MANAGEMENT OF DEBRIS FROM D\&D ACTIONS AT THE FEMP
}

by

CONF $-960212--28$

FROM D\&D ACTIONS AT THE FEMP
by

This abstract was prepared as an account of work sponsored by the United States Government, References herein to any specific commercial product process, or service by trade name, trademark, manufacturer, or otherwise does not constifute or imply ts endorsement, fecommendation or fayoring by the United States Government or any agency thereat tho ylews and opinions of atuhors expressed haren do not necessarily state or reflect those of the United States Government; or any agency theteof, or the: Fernald Environmental Restoration Management Corporation, its affiliates, or its parent compantes.

- Fernald Environmental Restoration Management Corporation with the U.S. Department of Energy under Contract No. DE-AC24-920R21972 
Page left intentionally blank 


\title{
STRATEGY FOR INTERIM MANAGEMENT OF DEBRIS FROM D\&D ACTIONS AT THE FEMP
}

\author{
John D. Throckmorton, \\ Todd R. Clark, Lewis C. Goidell \\ FERMCO \\ P.O. Box 538704 \\ Cincinnati, $\mathrm{OH} 45253-8704$
}

\author{
John S. Hall \\ U.S. Department of Energy \\ Fernald Area Office \\ P.O. Box 538705 \\ Cincinnati, $\mathrm{OH} 45253-8705$
}

\begin{abstract}
The Fernald site is currently performing a variety of decontamination and dismantlement (D\&D) activities in Operable Unit 3 under an approved CERCLA Record of Decision (ROD). The ROD and subsequent design documents specify the removal of the site structures, but a second ROD will govern the disposition of the resulting D\&D debris. Evolution of disposal concepts for wastes from other FEMP CERCLA operable units have resulted in the approval of an on-site disposal facility, which would be able to receive much of the D\&D wastes as well. Disposition proposals for FEMP D\&D debris are contained in the FEMP Operable Unit 3 Proposed Plan, currently being reviewed by the regulators. Since D\&D actions have been underway for some time at the site, and since the relative costs for on-site disposal ( $\$ 100$ million) are significantly less than those for off-site disposal ( $\sim 200$ million), waste streams potentially eligible for on-site disposal have been retained at the site in anticipation of ROD approval. These wastes have been stored within existing facilities, on existing pads, and on open foundations in both containerized and non-containerized forms. Eligible waste streams have been segregated by handling and storage requirements. Each waste stream has been individually examined to determine a least cost, safest, ALARA-based storage approach. Many materials previously handled in containers have been determined to be safe for uncovered outdoor storage, resulting in significant cost reductions and less overall handling of the materials.
\end{abstract}

\section{INTRODUCTION}

At the Fernald site, full scale remediation is about to commence. In total, four CERCLA Records of Decision and one Interim Record of Decision have been approved by the regulatory agencies covering excavation of waste pits and soils, extraction of groundwater, vitrification of processing residues, and D\&D of buildings. The final disposal of the generated wastes are expected to be dispositioned at several locations throughout the nation, including the Nevada Test Site (NTS), Envirocare of Utah, and the Fernald site itself. Of the remedial actions planned, the $D \& D$ program is currently underway with the $D \& D$ of one uranium processing complex complete, the full scale D\&D of two more underway, and the contract for the fourth about to be released. The eventual disposal of the materials generated by the D\&D actions are expected to be on-site within a sitewide On-Site Disposal Facility (OSDF). However, waste placement within the OSDF is not expected to commence until September 1997.

Under typical work conditions, wastes would not be generated until a disposal facility was available to receive the materials. However, the logistics and schedule of full scale remediation at the Fernald site do not allow this to happen. The OSDF is anticipated to hold approximately 2.5 million cubic yards of material. Approximately $90 \%$ of this material will be soils. Most of these soils are currently located in the former Production Area where uranium and thorium processing occurred. Due to the presence of the buildings and structures in the Production Area, the soils cannot be excavated for remediation until a significant portion of the D\&D is completed. In addition, it is the soils from the former Production Area that are necessary as a fill material to support debris placement within the OSDF. 
To resolve these issues and support remediation, Fernald has taken a proactive approach to accelerate the remediation project and is looking at new, innovative ways to accomplish the site mission. Fernald is looking beyond the typical approaches applied to site remediation; this has allowed the site to propose a 10 year accelerated remediation schedule. To support remediation and allow an accelerated schedule, debris must be generated early in the process, which will require interim storage until placement in the OSDF can occur.

\section{STRATEGY}

With the remediation scheduled to proceed in advance of the OSDF construction, several FEMP project objectives have been identified: 1) dispose of the majority of acceptable waste streams into the OSDF; 2) minimize shipment of OSDF acceptable waste streams to the NTS; 3) stage materials cost effectively to support future OSDF placement; 4) minimize new construction for storage locations; and 5) minimize costs associated with storage. To achieve these objectives, two specific alternatives have been evaluated including (1) containerization of all materials and (2) a combination of uncovered, bulk outdoor storage and containerization of the materials. The approach for each specific material type under the second option is detailed in Table $\mathrm{l}$.

\section{TABLE I DEBRIS SEGREGATION APPROACH}

\begin{tabular}{|c|c|c|}
\hline Material Category & Storage Configuration ${ }^{1}$ & Disposition \\
\hline Accessible Metals & Stockpile & On-Property \\
\hline Inaccessible Metals & Stockpile & On-Property \\
\hline Process-Related Metals & Containerize & Off-Site \\
\hline Painted Light-Gauge Metals & Stockpile & On-Property \\
\hline Concrete & Stockpile & On-Property \\
\hline Acid Brick & Containerize & Off-Site \\
\hline Non-Regulated $\mathrm{ACM}^{2,3}$ & Stockpile/Containerize & On-Property \\
\hline Regulated ACM & Containerize & On-Property \\
\hline Miscellaneous Materials ${ }^{3}$ & Containerize & On-Property \\
\hline
\end{tabular}

\footnotetext{
Notes:

1 Typical approach for storage of predominant materials. All hazardous and mixed waste debris will be containerized.

2 Transite will be handled separate from other Non-Regulated ACM. Transite is to be bandwrapped to pallets and stored in stockpile configuration

${ }^{3}$ Miscellaneous Materials can be containerized with other Non-Regulated ACM materials.
}

Three types of exposures or releases can be anticipated from uncovered, bulk outdoor storage: 1) direct radiation, 2) airborne releases, and 3) run on/runoff. Direct radiation exposures would likely increase as a result of uncovered, bulk outdoor storage. To address the potential for increased direct radiation exposure, ALARA concepts of maximizing worker distances from the 
piles would be utilized to minimize overall doses. An additional factor that will contribute to lowering direct radiation doses is the pile configuration providing some shielding.

Airborne releases would be minimized through actions taken during the D\&D projects. As part of the ongoing D\&D activities, all metal materials will be hydrocleaned to remove gross surface contamination levels. After this initial decontamination, only fixed contamination is expected on the materials and minimal airborne releases would be expected from uncovered, bulk outdoor storage. If elevated airborne releases are detected, surfactants would be used to minimize further releases.

The third potential for release is rainwater run on/runoff. To address this issue, all storage will occur on diked pads with run on/runoff control. The collected stormwater from these pads will be routed into the existing water treatment system for treatment prior to discharge. All storage areas within the former Production Area currently have stormwater collection. No new construction is anticipated to support the control of run on/runoff.

\section{EVALUATION}

To support the storage evaluation, a cost analysis was developed comparing the alternatives of containerizing all materials and allowing uncovered, bulk outdoor storage of some materials. To allow direct comparison, the materials that would be containerized under either alternative (i.e., friable ACM) were excluded.

Over the next two years until the OSDF is available, it is anticipated that approximately 81,000 cubic yards of bulked volume would be generated from D\&D activities. The bulked volume represents the increase in volume associated with containerizing a material and includes estimated void spaces. The bulking factors used to calculate these volumes are based on containerization data from the earlier D\&D projects at the site.

For the evaluation of the containerized alternative, the following costs were assessed: the purchase of containers; a radiological monitoring staff of five personnel throughout the two years; and the movement of materials from storage to the OSDF. No maintenance of the containers was assumed in the estimate of this alternative.

For the outdoor storage alternative, costs included in the estimate are: the purchase of containers; a radiological monitoring staff of five personnel throughout the two years; unloading the containers at the storage area; stacking materials into ten foot high piles; reuse of containers for 25 loads; maintenance of the container after every other use; shredding and disposal of unusable containers; and recontainerizing the material at the end of the two year storage period before being transported to the OSDF.

In both estimates, several items have been excluded because they would be necessary at the same rate under either alternative. These items are management staff and treatment of collected rainwater. Currently all rainwater collected within the former Production Area (including storage areas) is collected as stormwater and treated as necessary.

The cost to containerize all materials (option 1) has been estimated at approximately $\$ 22$ million and the cost to store materials as identified in Table I (option 2) is approximately $\$ 5.5$ million. The significant contributor to the cost differential is the cost of the containers and the requirement to dispose of the additional container volume after 25 reuses. If all 2.2 million 
cubic feet of material is containerized, approximately 2,900 containers would be purchased. This cost represents approximately $95 \%$ of the $\$ 22$ million dollar cost estimate.

In contrast, under the outdoor storage alternative, 126 containers would be purchased to facilitate movement of materials from the D\&D action to storage and from storage to the OSDF. The containers were estimated to be disposed within the OSDF under each alternative. After two years of storage, these containers will have begun to deteriorate and would be radiologically contaminated and refurbishment is not likely. If recycling is not feasible, then the containers would be shredded and dispositioned. Similarly, after 25 uses under the outdoor storage alternative, the container is estimated to be excessively damaged through wear and tear and unable to be refurbished. At that point, these containers would also be shredded and dispositioned. As a result of this evaluation for these materials, uncovered, bulk outdoor storage is the preferred proposed alternative.

To support the implementation of this strategy, the site adopted the use of a CERCLA removal action to gain regulatory approval. A current and ongoing removal action that addresses the improved storage of soil and debris has been modified to address the sitewide storage issues for debris that will be required over the next two years. The strategy proposed within the removal action was to stage all materials by material category as segregated under the D\&D project. The D\&D project will segregate materials into like categories. For example, all nonfriable ACM is one category while all painted, light gauge metals is another category. Each material category will be staged in a separate pile or containerized as appropriate.

Once generated and segregated, the staging would occur on storage pads with run on/runoff collection. Most materials would be moved to a central staging area that is the Plant 1 Pad. This facility has approximately 375,000 square feet of usable space for storage. In addition to this space, as buildings are removed, the foundations will be utilized to stage structural steel and other materials from the building itself.

To support the safe and effective storage of these materials, air monitoring stations would be established around staging areas to track and evaluate impacts to workers and the environment. As necessary, surfactants could be used to control and minimize airborne releases.

\section{CONCLUSION}

Many DOE sites will have quickly dismissed the possibilities of on-property disposal and noncontainerized storage as a reaction to external environmental protection pressures, when in reality, many materials can be safely stored in less costly ways. This proposed strategy for the safe, effective storage of materials has utilized lessons learned from the Weldon Springs Remedial Action Project. The combination of material containerization and uncovered, bulk outdoor storage is a cost effective method for staging the D\&D generated materials until material placement can occur within the OSDF. At Fernald, an approximate cost savings of $\$ 16$ million can be realized. The approach to bulk store materials utilized by the Fernald site is protective of the workers, the public, and the environment. The approaches and lessons learned at the Fernald site could benefit other DOE sites within the complex.

\section{REFERENCES}

U.S. Department of Energy, "Removal Action 17 Work Plan, Revision 3, Improved Storage of Soil and Debris, Final," prepared by Fernald Environmental Restoration Management Corporation, December 1995. 